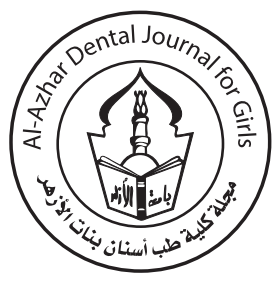

\title{
Effect of Two Occlusal Patterns of Implant Retained Overdenture by Two Attachment Systems on the Electromyographic Activity
}

\author{
Marwa G. Mahmoud ${ }^{1 *}$, Ahmed A. Shaaban ${ }^{2}$, Mai S. Attia ${ }^{3}$, Mostafa M. Abdel-Ghany ${ }^{4}$
}

Codex : 01/21.01

azhardentj@azhar.edu.eg

http://adjg.journals.ekb.eg

DOI: $10.21608 /$ adjg.2021.10714.1132

Restorative Dentistry

(Removable Prosthodontics, Fixed

Prosthodontics, Endodontics, Dental Biomaterials, Operative Dentistry)

\section{KEYWORDS}

Implant supported prosthesis, Occlusion, Electromyography.

\begin{abstract}
Purpose: To assess the effect of two attachment systems ball and socket and locator attachments and two occlusal patterns; bilateral balanced and monoplane occlusion on the electromyographic activity of temporalis and masseter muscles in mandibular implant retained overdenture. Material and Methods: Twelve male completely edentulous patients were selected from the outpatient clinic, Prosthodontic department, Faculty of Dental Medicine for Girls, Al-Azhar University. The patients were divided into two different groups: Group I received the Locator attachment and Group II received ball and socket attachment. All patients in both groups were divided equally into two subgroups: In subgroup 1: Patients received complete dentures with bilateral occlusal pattern and subgroup 2 the patients received complete denture with monoplane occlusion. Electromyographic activity for masseter and temporalis muscles were made after one month and three months for soft food and hard food. In subgroup 1 the dentures were replaced by the dentures with monoplane occlusion while in subgroup 2 the dentures were replaced by the denture with bilateral balanced occlusion. In group I and II attachments were switched and the same steps were followed for subgroups. The data were collected. Results: When using denture with bilateral balanced occlusion with locator attachment showed low electromyographic activity on the masseter and temporalis muscle than the denture with monoplane occlusion and there was no significant difference when using soft food during the first month while after 3 months there were significant difference. When using ball \& socket attachments there were significant difference when using soft and hard food when using hard food there are significant difference between the subgroups. Conclusion: The two implant retained
\end{abstract}

- Paper extracted from doctor thesis titled "Effect of Two Occlusal Patterns of Implant Retained Overdenture by Two Attachment Systems on the Electromyographic Activity".

1. Removable Prosthodontic Specialist of Ain Shams Medical Affairs, Cairo, Egypt.

2. Lecturer of Removable Prosthodontics, Faculty of Dental Medicine, Future University, Cairo, Egypt.

3. Associate Professor of Oral Medicine, Periodontology, Diagnosis and Radiology, Faculty of Dental Medicine for Girls, Al-Azhar University, Cairo, Egypt.

4. Professor of Removable Prosthodontic, Former Dean of Faculty of Dental Medicine for Girls, Al-Azhar University, Cairo, Egypt.

* Corresponding author email: marwagamal34@yahoo.com 
mandibular overdenture with the locator attachment showed relatively low electromyographic activity of the masticatory muscles (masseter and temporalis) than with ball and socket attachment and high electromyographic activity of the masticatory muscles (masseter and temporalis) with monoplane occlusion than with bilateral balanced occlusion.

\section{INTRODUCTION}

Dental implant treatment provides patients with better stability and improved function with the prostheses. Overdenture retained by implants will save the acceptable support, retention and stability of denture, and allows functional recoveries via a denture flange. However, for some edentulous patients with certain unfavorable oral conditions or financial concerns, support for fixed partial dentures is not affordable ${ }^{(1)}$.

Therefore, overdentures preserved or supported by implants are adopted. In general, implant retained or supported overdentures can be applied by placing as few as one or up to several implants and then using attachments to provide retention for the denture. Implant supported mandibular overdenture presents an unfailing and simple solution to denture support, retention and stability ${ }^{(2,3)}$.

There are many studies made to investigate the effectiveness of mandibular overdentures attachment systems in order to emphasize which system bargains best efficiency on the long term control. There also are studies created to gauge stress produced on completely different attachment sorts over angular and vertical strength and stress distribution around bone, implants, and prosthetic components ${ }^{(4)}$.

Implant supported mandibular overdenture on two separate implants has been recognized as one of the most appropriate first choice treatment for the edentulous people. Prospect long run clinical studies have established that not solely will the location of implants enhance the stability, retention support of dental appliance, however conjointly reduces the speed of residual ridge resorption ${ }^{(5)}$.

\section{MATERIAL AND METHODS}

Twelve male completely edentulous patients were selected from the outpatient clinic, Prosthodontic department, Faculty of Dental Medicine for Girls, Al-Azhar University. The patients were apparently free from any oral or debilitating systemic diseases, ages range from 55-60 years, Residual alveolar ridges of maxilla and mandible covered by healthy, firm, compressible mucosa, free from any temporomandibular joint disorders and have Angle's class I jaw relation.

Radiographic template was constructed, finished, polished and checked in patient's mouth to be used afterwards for radiographic evaluation and as a surgical stent. Then a conventional upper and lower complete dentures were made for all patients following the regular steps.

Bilateral mandibular implants were inserted in the canine area. After osseointegration, second stage surgery was carried out. The surgical stent was used to detect the implant position and small incision was done over the site of implant fixture, implant cover was unscrewed and removed. The healing collars were placed for 10 days.

The Patients then were divided into two groups according to attachments type used: Group I received the Locator attachment; Group II received ball and socket attachment. (Fig 1) Pickup conventional technique was done to attach the denture to the implants. Moreover, all patients in each group were divided equally into two subgroups patients delivered complete dentures with bilateral occlusal pattern or monoplane occlusion. The patients were leaved for one month for adaptation period. Electromyographic activity for masseter and temporalis muscles was made after one month and three months for soft food (banana) and hard food (carrots). Then in subgroups the dentures replaced by the denture with opposite occlusion.

The patients then were leaved for one month for adaptation period. Electromyographic activity for masseter and temporalis muscles was made after one month and three months for soft food (banana) 
and hard food (carrots). After that in group I locator was replaced by ball and socket attachments. While, in group II the ball and socket was replaced by locator attachments and the patients were leaved for one- month adaptation period. All patients in each group were divided equally into two subgroups. In both subgroups the patients were delivered complete dentures with bilateral occlusal pattern and monoplane occlusion alternatively. Electromyographic activity for masseter and temporalis muscles after one month and three months for soft food (banana) and hard food (carrot). The data were collected.

Electromyographic activity measurement was done as follows: One month later each set of occlusion adapted by the patient, electromyographic activities of muscles were tested. Surface electromyographic records were got from the right and the left masseter and right and left temporalis muscles by an electromyographic machine. The set used included a stimulator, oscilloscope, amplifier, filter and gain. Electrodes transmitted signals to the main unit. The signals were amplified, filtered and displayed on the oscilloscope then printed on paper. The electrodes were silver chloride disc electrodes soldered into a conducting wire. (Fig 2,3)

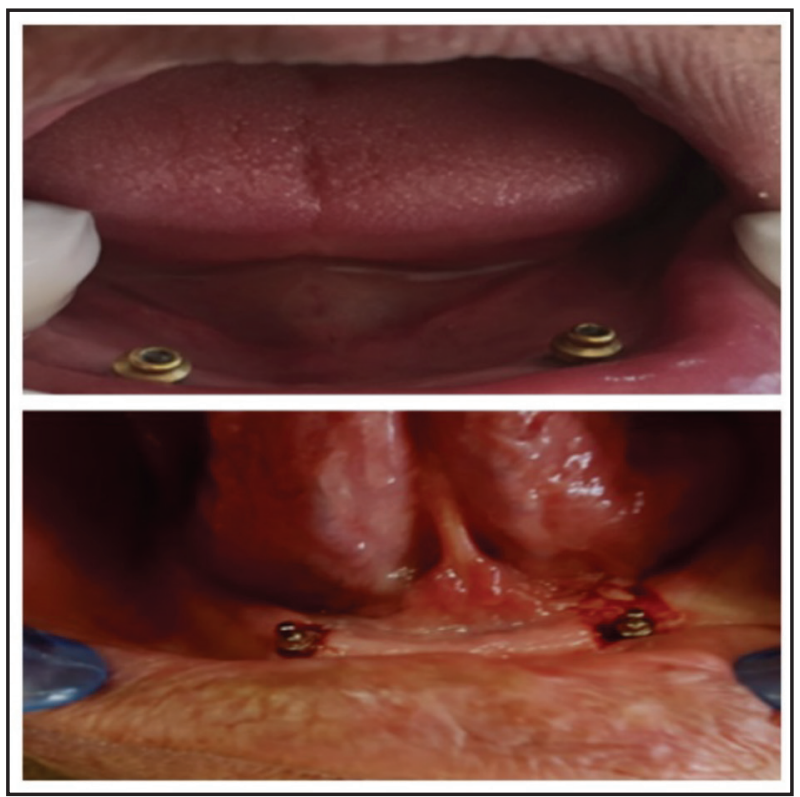

Figure (1) Different attachment systems; locator and ball and socket attachment

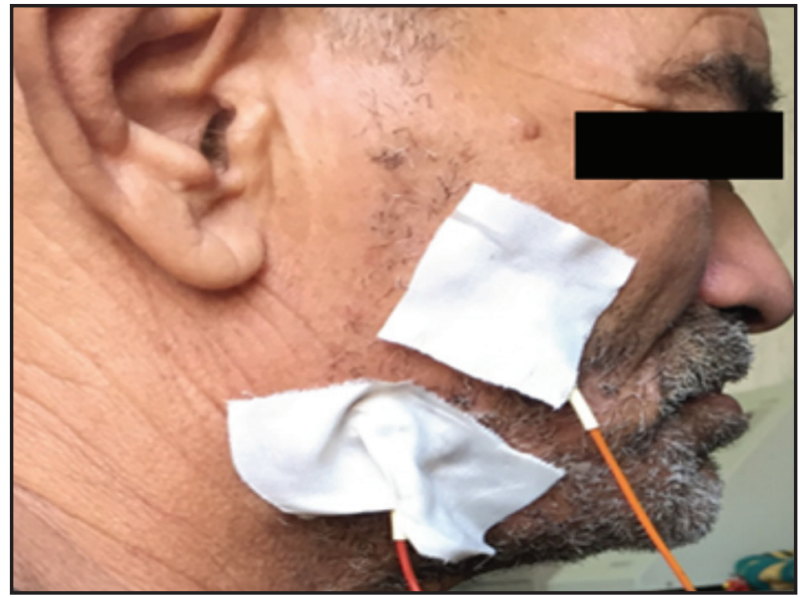

Figure (2) Electrodes of the electromyogram on the masseter muscles

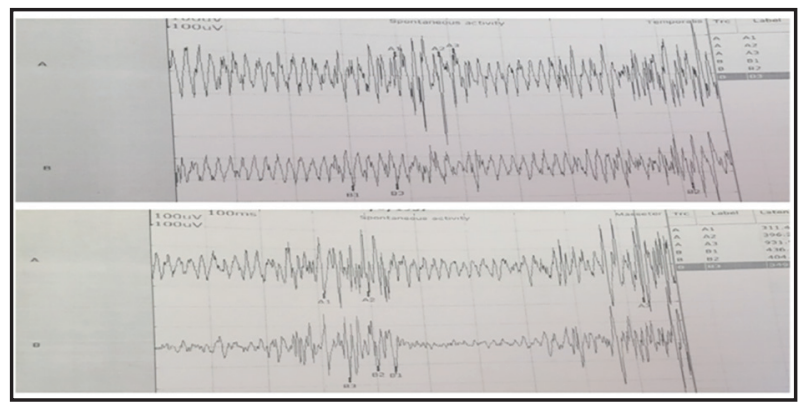

Figure (3) Electromyographic activity for temporalis and masseter muscles

\section{RESULTS}

\section{Electromyographic activity:}

There was low electromyographic activity of the masseter muscle with soft and hard food at one and three months using locator attachment for denture with bilateral balanced occlusion than the denture with monoplane occlusion.

The use of ball \& socket attachments showed no significant difference in the electromyographic activity of the masseter muscle between denture with bilateral balanced occlusion and denture with monoplane occlusion when using soft food while in using hard food showed a significant difference between the subgroups. (Table 1) 
Table (1) Electromyographic activity of Masseter muscle using soft food and hard food between different occlusions:

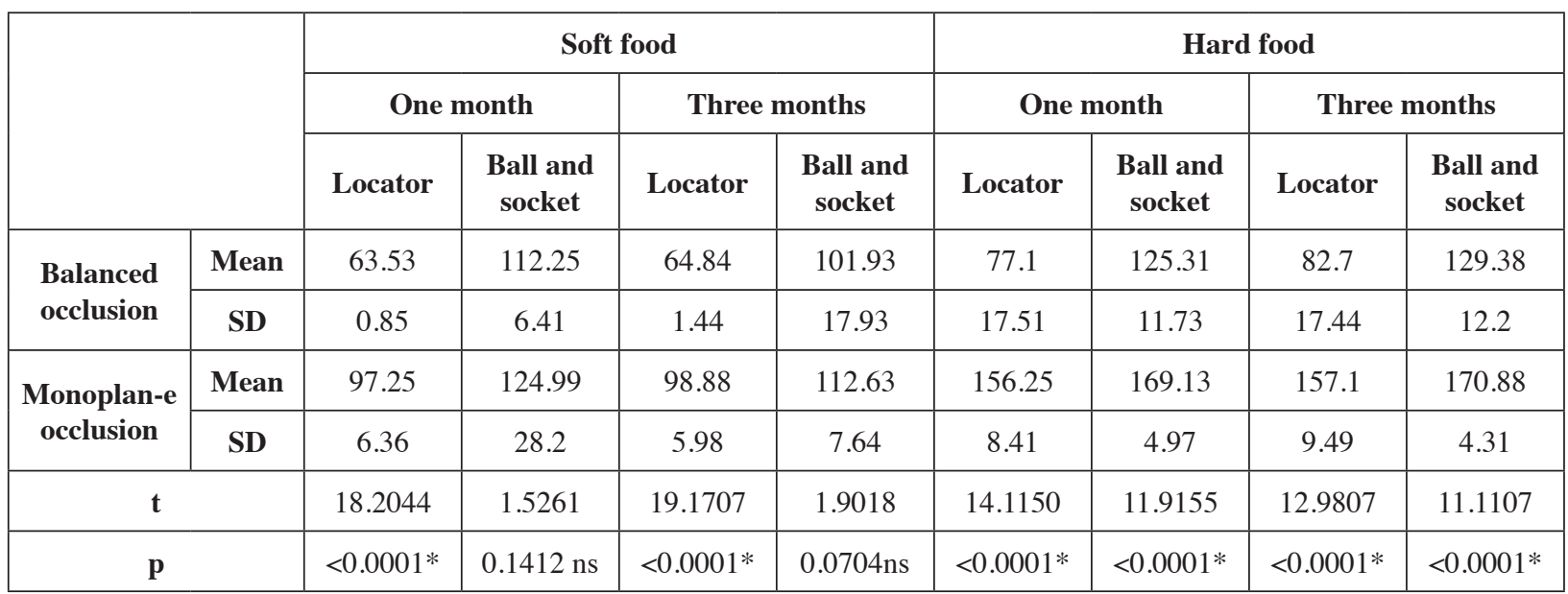

Significance level $P<0.05$, *significant, $n s=$ non-significant

The use of locator attachment for denture with bilateral balanced occlusion showed lower electromyographic activity of the temporalis muscle with soft and hard food at one and three months than the denture with monoplane occlusion. There was no significant difference when using soft food during the first month for both types of occlusion while 3 months later there was significant difference.
The use of ball \& socket attachments showed a significant difference between denture with bilateral balanced occlusion and dentures with monoplane occlusion when using soft food while using hard food there was a significant difference between the subgroups. (Table 2)

Table (2) Electromyographic activity of Temporalis muscle using soft and hard food between different occlusions:

\begin{tabular}{|c|c|c|c|c|c|c|c|c|c|}
\hline & & \multicolumn{4}{|c|}{ Soft food } & \multicolumn{4}{|c|}{ Hard food } \\
\hline & & \multicolumn{2}{|c|}{ One month } & \multicolumn{2}{|c|}{ Three months } & \multicolumn{2}{|c|}{ One month } & \multicolumn{2}{|c|}{ Three months } \\
\hline & & Locator & $\begin{array}{c}\text { Ball and } \\
\text { socket }\end{array}$ & Locator & $\begin{array}{c}\text { Ball and } \\
\text { socket }\end{array}$ & Locator & $\begin{array}{c}\text { Ball and } \\
\text { socket }\end{array}$ & Locator & $\begin{array}{c}\text { Ball and } \\
\text { socket }\end{array}$ \\
\hline \multirow{2}{*}{$\begin{array}{l}\text { Balanced } \\
\text { occlusion }\end{array}$} & Mean & 127.5 & 135.38 & 104.88 & 120.88 & 148.71 & 177.98 & 149.88 & 157 \\
\hline & SD & 9.65 & 16.24 & 11.4 & 15.62 & 44.43 & 52.25 & 38.52 & 35.15 \\
\hline \multirow{2}{*}{$\begin{array}{l}\text { Monoplane } \\
\text { occlusion }\end{array}$} & Mean & 138.26 & 138.7 & 128.33 & 136.56 & 201.13 & 207.63 & 202.51 & 208.56 \\
\hline & SD & 37.64 & 33.1 & 9.05 & 16.56 & 9.58 & 9.49 & 9.34 & 9.91 \\
\hline \multicolumn{2}{|l|}{$\mathbf{t}$} & 0.9592 & 0.3119 & 5.5809 & 2.3861 & 3.9952 & 1.9341 & 4.5997 & 4.8907 \\
\hline \multicolumn{2}{|l|}{$\mathbf{p}$} & $0.3479 \mathrm{~ns}$ & $0.758 \mathrm{~ns}$ & $<0.0001 *$ & $0.0261 *$ & $0.0006^{*}$ & $0.0661 *$ & $<0.0001 *$ & $<0.0001 *$ \\
\hline
\end{tabular}

Significance level $p<0.05$, *significant, $n s=$ non-significant 


\section{DISCUSSION}

Bilateral balanced occlusion was represented by several authors because it promotes higher masticatory operate by conveyance a bigger quantity of chewing surfaces into contact at each movement. That is a line with the current study and not coincide with other study that found no distinction in muscle action between bilateral balanced occlusal scheme and canine guided occlusal concept in complete denture occlusion ${ }^{(6-8)}$.

These results weren't additionally coinciding with other study found that balanced occlusal scheme didn't improve chewing potency compared with other type of occlusion. Another study assessed masticatory potency in removable complete denture with balanced occlusion and found that no applied mathematics important distinction between different types of occlusion ${ }^{(9)}$.

Another review was indicated that the treatment result with mandibular implant overdenture isn't associated with attachment system. Additional study showed no important distinction in chew potency with electromyography between ball and socket and other type of attachment using chewing gum and in two implant retained removable overdenture prosthesis. In a different study shown that masticatory potency of implant overdentures maintained by magnet and locater attachments and also results showed no distinction between each variety of the attachment systems ${ }^{(10-12)}$.

Current study in which results were differing directly and showed increased activity of muscle with ball and socket attachment more than with locater attachment which in such case may be accredited to increase the retention gained by locater attachments compared with different attachments as it provides retention that have effect on retention and stability of corrective and so masticatory activity of edentulous patient ${ }^{(13)}$.

In contrary to the current study during which the utmost biting force was recorded in each locater and ball attachments and therefore the results showed low recordings in electromyogram with locater attachment $^{(14,15)}$.

On the other hand, this study agreed with other study which was made to detect results of overdenture supported by implant on the chewing force of muscles and recorded no significant. Another study used electromyogram to judge performance of striated muscle and facial muscle with totally different sizes of attachments and showed no distinct difference among studied muscles ${ }^{(16)}$.

The present study is in agreement with a previous study that compared retention and masticatory potency of system of different attachments for holding two implant retained complete overdentures, it showed that locator attachments provided higher long run masticatory effectiveness ${ }^{(17)}$.

Finding of the study come in line with others who noted that the accrued electromyogram activity could also be thanks to accrued vertical dimension resulting in accrued muscle activity throughout most voluntary clenching. This finding is additionally in line with another study which conjointly showed higher mean electromyogram activity once chew soft and hard food during this study. This coincides with findings showed that tougher food constancy needed upper muscle activity levels due to higher muscle force required to portion fatiguing food. The results are in agreement with results which found that tougher foods needed higher chew rates, higher electrical activity of the facial muscle, and better relative shrinkage periods, in the course of shorter cycle durations $^{(18)}$.

\section{CONCLUSIONS}

The two implant retained mandibular overdenture with the locator attachment showed relatively low electromyographic activity of the masticatory muscles (masseter and temporalis) than with ball and socket attachment and high electromyographic activity of the masticatory muscles (masseter and temporalis) with monoplane occlusion than with bilateral balanced occlusion. 


\section{REFERENCES}

1. Thomason JM, Feine J, Exley C, Moynihan P, Müller F, Naert I, et al. Mandibular two implant-supported overdentures as the first choice standard of care for edentulous patients--the York Consensus Statement.Br Dent J, 2009; 207: $185-6$.

2. Kim HY, Lee JY, Shin SW, Bryant SR. Attachment systems for mandibular implant overdentures, a systematic review. J Adv Prosthodont, 2012; 4: 197- 203.

3. van der Bilt A, van Kampen FM, Cune MS. Masticatory function with mandibular implant-supported overdentures fitted with different attachment types. Eur J Oral Sci, 2006; 114: $191-6$.

4. Feine J, Maskawi K, de Grandmont P, Donohue WB, Tanguay R, Lund JP. Within-subject comparisons of implant-supported mandibular prostheses: Evaluation of masticatory function. J Dent Res, 1994; 73: 1646- 56.

5. Ohguri T, Kawano F, Ichikawa T, Matsumoto N. Influence of occlusal scheme on the pressure distribution under a complete denture, Int J Prosthodont, 1999; 4: 353-8.

6. Grunert I, Kofler M, Gausch K, Kronenberg M. Masseter and temporalis surface electromyography in patients wearing complete dentures comparing anterior and posterior occlusal concepts a pilot study. J Oral Rehabil,1994; 21: $337-47$.

7. Farias Neto A, Mestriner Junior W, Carreiro Ada F. Masticatory efficiency in denture wearers with bilateral balanced occlusion and canine guidance. Braz Dent J, $2010 ; 21: 165-9$.

8. Abd Elmonem E. Colorimetric comparative analysis of masticatory efficiency in complete denture wearers with two different occlusal concepts. M.Sc. Thesis, Removable Prosthodontics Department, Faculty of Dentistry, Alexandria University, Egypt, 2014.

9. Elsyad MA, Hegazy SA, Hammouda NI, Al-Tonbary GY, Habib AA. Chewing efficiency and electromyographic activity of masseter muscle with three designs of implantsupported mandibular overdentures, A cross-over study. Clin Oral Impl Res, 2014; 25: 742-8.

10. Sun X, Zhai JJ, Liao J, Teng MH, Tian A, Liang X. Masticatory efficiency and oral health-related quality of life with implant-retained mandibular overdentures. Saudi Med J, 2014; 35: 1195- 202.

11. Cheng T, Sun G, Huo J, He X, Wang Y, Ren YF. Patient satisfaction and masticatory efficiency of single implantretained mandibular overdentures using the stud and magnetic attachments, J Dent, 2012; 40: 1018- 23.

12. Bilhan H, Geckili O, Mumcu E, Cilingir A, Bozdag E. The influence of implant number and attachment type on maximum bite force of mandibular overdentures, a retrospective study. Gerodont, 2012; 29: 116- 20.

13. Ucankale M, Akoglu B, Ozkan Y, Ozkan Y. The effect of different attachment systems with implant retained overdentures on maximum bite force and EMG. Gerodont, 2012; 29: 24-9.

14. Bakke M, Holm B, Gotfredsen K. Masticatory Function and Patient Satisfaction with Implant-Supported Mandibular Overdentures, A Prospective 5-Year Study, Int J Prosthodont, 2002;15: 575- 81.

15. Sobhy MS, Abd-Elakher M. Effect of Different Attachment Size on the Muscle Activity in Single Implant Retained Mandibular Over denture. Current Sci Int, 2012; 21: 18- 20.

16. Shady M, Emera R, Hegazy SA, Kenawy M. Bar Locator Versus Bar Clip Attachment for Implant Assisted Mandibular Overdenture. Dent J, 2014;10:1-5.

17. Darwish A, Segaan L, El Shorbagy Z, Abd El Hamid A. Electromyographic activity of masseter muscle of patients wearing complete dentures with different occlusal concepts. J Prosthet Dent 2010; 103: 53-5.

18. Karkazis HC. EMG activity of the masseter muscle in implant supported overdenture wearers during chewing of hard and soft food. J Oral Rehabil, 2002; 29: 986-91. 